\title{
PROJETO INCLUSÃO ESCOLAR NA ESCOLA MUNICIPAL PREFEITO ALVARO BRANDÃO EM DOURADOS-MS
}

\author{
PROYECTO INCLUSION ESCOLAR EN LA ESCUELA MUNICIPAL PREFEITO \\ ALVARO BRANDÃO EN DOURADOS-MS
}

Flávia Paula Nogueira Aranda ${ }^{1}$ Regina Margareth de Oliveira Queiroz dos Santos ${ }^{2}$

Nelsi Zollett ${ }^{3}$

Raquel Blanco Aquino ${ }^{4}$

\begin{abstract}
Resumo: Este artigo tem como objetivo apresentar e divulgar o Projeto de Leitura e Escrita realizado na escola Escola Municipal Prefeito Álvaro Brandão, no município de Dourados-MS; bem como refletir sobre a inclusão escolar e intervir no combate à discriminação dentro da escola. Tal projeto foi realizado durante o ano de 2018 e abordando o tema: A Inclusão Escola. A ação teve como protagonistas alunos e professores da turma do primeiro ano do ensino fundamental. Metodologicamente, utiliza-se uma abordagem qualitativa, pautada nas experiências vivenciadas durante a realização do projeto, além de análise documental e pesquisa de campo. Tais experiências apresentaram contribuições significativas para o desenvolvimento cognitivo, afetivo e social das crianças, além de agregar conhecimentos empíricos aos professores nos aspectos relacionados às diversidades e diferenças dentro do ambiente escolar.
\end{abstract}

Palavras-chave: Projeto escolar. Leitura. Inclusão escolar.

Abstract: Este artículo tiene como objetivo presentar y difundir el Proyecto de Lectura y Escritura realizado en la Escuela Municipal Prefeito Alvaro Brandão, en el municipio de Dourados-MS; Bien como reflexionar sobre la inclusion e intervenir en la lucha contra la discriminación dentro de la escuela. Este projecto fue se realizado durante el año 2018 y abordó el tema: La inclusión escolar y tuvo como protagonistas a estudiantes y maestros de la clase del primer año de la escuela primaria. Metodológicamente, se utiliza un enfoque cualitativo para este artículo, basado en las experiencias vividas durante la realización del proyecto, así como el análisis documental y la investigación de campo. Estas experiencias hicieron contribuciones significativas al desarrollo cognitivo, afectivo

\footnotetext{
${ }^{1}$ Mestre em Educação pela Universidade Federal da Grande Dourados (UFGD).

${ }^{2}$ Pedagoga pela Universidade Estadual de Mato Grosso do Sul (UEMS). Especialista em Educação Especial.

${ }^{3}$ Pedagoga pela Universidade Estadual de Mato Grosso do Sul (UEMS). Especialista em Atendimento Educacional Especializado (AEE) da Rede Municipal de Ensino de Dourados-MS.

${ }^{4}$ Pedagoga pela Universidade Federal da Grande Dourados (UFGD). Supervisora do Programa Institucional de Bolsa de Iniciação à Docência da Universidade Estadual de Mato Grosso do Sul (PIBID-UEMS).
} 
y social de los niños, además de agregar conocimiento empírico a los maestros em aspectos relacionados com la diversidad y las diferencias dentro del entorno escolar.

Key-words: Proyecto escolar. Lectura. Inclusión escolar.

\section{INTRODUÇÃO}

O presente artigo apresenta o Projeto de Leitura e Escrita desenvolvido na Escola Municipal Prefeito Álvaro Brandão, no município de Dourados, Mato Grosso do Sul.Tal projeto teve como objetivo refletir sobre a complexidade do tema e colocar em prática maneiras de intervenção para combater a discriminação das diferenças dentro do ambiente escolar.

Afinal, a Constituição Federal é expressiva em seu artigo 3. ${ }^{\circ}$, inciso IV, pelo qual se afirmar a necessidade de "promover o bem de todos sem preconceitos de origem, raça, sexo, cor, idade e quaisquer outras formas de discriminação". Tal legitimidade confirmada no artigo 206, que estabelece que o ensino deve ser ministrado tendo como um dos princípios "igualdade de condições de acesso e permanência na escola", e, ainda, coloca como dever de o Estado promover o ensino garantindo, conforme inciso III do artigo 208, "atendimento educacional especializado aos portadores de deficiência, preferencialmente, na rede regular de ensino" (BRASIL, 1988).

Assim, a escola inclusiva contribui nessa direção quando propõe a adaptação do currículo como observância a construção de estratégias e recursos que viabilizem a escolarização do aluno com deficiência. Para isso, é essencial que haja adequações dos processos de avaliação e o estabelecimento de critérios ou mesmo indicadores de sucesso ou fracasso do público-alvo da educação especial, também recomendam investimentos dessa natureza, como na formação continuada de docentes, para o aprofundamento da avaliação educacional desses alunos.

Diante das prerrogativas legais, a escola tem como obrigação promover a formação plena do ser humano em idade escolar, ou seja, formação social, cognitiva, afetiva e psicológica. Além de, ainda, oportunizar a todos os alunos (crianças, adolescentes e jovens) diferentes possibilidades de aprendizagem, contemplando as especifidades e limitações de cada um. Nesse sentido podemos afirmar que 
[...] a escola entendida como lugar social das aprendizagens intencionadas e sistemáticas, sendo evidente que esta forma de aprendizagem supõe e se refere à materialidade e concretude das aprendizagens que se estruturam nas vivências cotidianas dos específicos e diversificados lugares e tempos sociais, âmbitos linguísticos específicos em que vivem e atuam os seres humanos (MARQUES, 2006, p.10).

Percebe-se que a função da escola em termos de formação humana é bastante complexa, principalmente porque é um espaço fértil de diversidade, e cabe ao professor a responsabilidade de se posicionar frente a qualquer tipo de preconceito e discriminação.

Embora a temática sobre "Inclusão Escolar" tenha conquistado espaço na mídia, nos discursos políticos, nas pesquisas acadêmicas e consequentemente, na legislação brasileira, a inclusão escolar na contemporaneidade ainda é bastante complexa e contraditória. Contudo, a importância de conscientizar a comunidade escolar que a educação inclusiva é um direito:

[...] para que possamos romper com preconceitos e estereótipos, visando a eliminação de todas as barreiras, em busca de equidade, respeitando as diferenças pessoais e buscando a igualdade de oportunidades a todos. (GARCEZ; CONCEIÇÃO, 2015, p.10)

\section{METODOLOGIA}

Em termos de aportes metodológicos, utilizou-se para essa pesquisa o método qualitativo pois, conforme observa Godoy (1995 p.21), "a abordagem qualitativa, não se apresenta como uma proposta rigidamente estruturada, ela permite que a imaginação e a criatividade levem os investigadores a propor trabalhos que explorem novos enfoques", sendo possível analisar qualitativamente o processo de desenvolvimento do projeto de leitura e escrita.

Trabalhou-se com análise documental ao se apropriar de documentos específicos da instituição escolar, como o Projeto Político Pedagógico (PPP), o Regimento Escolar, o Referencial Curricular do município, todos pautados na Lei maior que rege a educação básica, sobretudo a etapa do ensino fundamental, o qual é nosso foco, a saber a Lei de Diretrizes e Bases da Educação (LDB/1996). 
Cabe destacar que, segundo Shiroma, Campos e Garcia (2005, p. 433), na análise documental os textos são considerados como “[...] produto e produtores de orientações políticas no campo da educação", cuja “difusão e promulgação geram também situações de mudanças ou inovações, experienciadas no contexto das práticas educativas".

Assim, diante do exposto até aqui, segue o relato das práticas e experiências vivenciadas pelos alunos e pelas professoras durante o desenvolvimento do Projeto Leitura e Escrita na Escola Municipal Prefeito Alvaro Brandão.

\section{DESENVOLVIMENTO}

\section{Breve Características da Escola Municipal Prefeito Álvaro Brandão}

A Escola Municipal Prefeito Álvaro Brandão foi criada no dia 21 de outubro de 1976, pelo decreto ${ }^{\circ} 611$ do dia 21/10/76, situa-se à Rua Filomeno João Pires, n. ${ }^{\circ} 1460$, no bairro João Paulo II. Com localização periférica urbana, oferece os níveis de modalidade de ensino em Educação Infantil (pré-escolar) e Ensino Fundamental de $1^{\circ}$ ao $9^{\circ}$ ano. É mantida pela Prefeitura Municipal, através da Secretaria Municipal de Educação, e pertence à categoria da Escola convencional, inscrita no Cadastro de Pessoas Jurídicas sob o n ${ }^{\circ} 33.752 .270 / 0001-08$.

Possui aproximadamente 860 alunos frequentando, distribuídos em 28 turmas e 14 salas de aula, com quatros coordenadores pedagógicas, 57 professores, 23 funcionários administrativos (PROJETO POLÍTICO PEDAGOGICO, 2018).A diretora atual é a Coordenadora Pedagógica Marilda Cabreira Leão. Os educadores desta unidade educativa são formados em suas respectivas áreas de conhecimento, sendo que dos cinquenta e sete professores, $99 \%$ possuem licenciatura plena e $80 \%$ destes concluíram a pós-graduação em nível lato-sensu.

O papel social da escola é de oferecer um ensino de qualidade, garantindo o acesso e a permanência dos alunos na escola, formando cidadãos conscientes de sua importância na sociedade. A instituição almeja buscar a excelência nos serviços prestados (PROJETO POLÍTICO PEDAGÓGICO, 2018).

A Escola Municipal Prefeito Álvaro Brandão possui esse nome em homenagem ao segundo prefeito do município de Dourados pelo Partido Evolucionista, exerceu seu mandato durante os anos de 1937 a 1943. Foi na gestão do prefeito Álvaro Brandão a 
construção da primeira escola, em 1940, no bairro Cabeceira Alegre. Na época em que o coronel Álvaro Brandão foi prefeito, o Brasil era governado por Getúlio Vargas (PROGRESSO, 2015).

\section{Desenvolvimento e Realização do Projeto Leitura e Escrita com o tema}

\section{"Inclusão Escolar"}

A iniciativa do projeto leitura e escrita na escola partiu da gestão da instituição. A prática de desenvolver projetos nas escolas e Centros de Educação Infantil Municipais (CEIMS) é bastante comum e faz parte da proposta curricular da Secretaria Municipal de Educação (SEMED), conforme expresso no regimento interno da instituição de ensino.

Art. 142. Esta Unidade Escolar desenvolverá, sempre que necessário e dentro de suas possibilidades, projetos especiais com a finalidade de atender aos interesses da comunidade escolar, podendo firmar convênio e propor termo de cooperação com entidades públicas e privadas, submetendo-se apreciação do Conselho Escolar (REGIMENTO ESCOLAR, 2015, p.52).

Seguindo o regimento interno, a proposta sobre o desenvolvimento do projeto foi abordada logo no início do ano letivo, durante a formação pedagógica interna, quando foram definidos os critérios e objetivos do projeto, que tinha como foco principal estimular a leitura e a escrita nos alunos do ensino fundamental.

A partir da divulgação do projeto, a coordenação pedagógica sugeriu que os professores de cada turma escolhessem um tema a ser trabalhado durante o decorrer do ano letivo, o que foi aceito por unanimidade entre os presentes.

As professoras dos primeiros anos do ensino fundamental do período vespertino decidiram trabalhar com o tema "Inclusão Escolar", visto que nas duas salas de aulas possuíam alunos com deficiências (Deficiência Intelectual e Síndrome Treacher Collins). Cabe destacar o que Silva (2012) observa sobre a inclusão escolar:

A inclusão educacional trata do direito de todos à escolarização. No interior desses todos, lemos que as pessoas com diferentes deficiências, transtornos globais do desenvolvimento e altas habilidades/superdotação estão plenamente contempladas (SILVA, 2012, p.163). 
Essa questão já vem expressa na legislação educacional nacional e acatada pelos documentos oficiais do munícipio, que reafirmam o compromisso na garantia do direito à educação, bem como a garantia da inclusão, já que "a escola é um espaço social propício para a formação cidadã, pois acolhe toda a diversidade, e deve, portanto, promover o respeito e a valorização das diferenças” (REFERENCIAL CURRICULAR MUNICIPAL, 2016, p.14).

Assim, a escolha do tema do projeto partiu da demanda presente na sala de aula, visto que a inclusão faz parte do conteúdo do componente curricular entendido como importante temática a ser abordada não só na sala de aula, mas em todos os espaços do ambiente escolar, conforme evidenciado por Mantoan (2003, p. 24):

A inclusão implica uma mudança de perspectiva educacional, pois não atinge apenas alunos com deficiência e os que apresentam dificuldades de aprender, mas todos os demais, para que obtenham sucesso na corrente educativa geral.

Portanto, partindo desse pressuposto, as professoras acreditaram que as atividades desenvolvidas com os alunos dos primeiros anos atingiriam positivamente desde os menores até os adolescentes, pois seriam posteriormente apresentadas na feira cultural da escola, alcançando até mesmo os familiares. Estes teriam contato com as apresentações e com as atividades que foram produzidas pelos alunos em sala de aula no decorrer do ano letivo.

Os alunos com deficiência assim como os que não possuem nenhum tipo de deficiência são igualmente cidadãos de direitos e o combate a toda e qualquer forma de discriminação e preconceito não pode ser negligenciado dentro do espaço escolar; pelo, contrário, deve ser discutida e dialogada juntamente com toda a comunidade, para que, a partir do conhecimento sobre as deficiências e limitações, seja feita uma reflexão sobre meios e ações que venham contribuir para a socialização do aluno não somente com o professor da sala de aula, mas com todos os demais sujeitos que fazem parte do ambiente escolar.

Sendo assim, a proposta inicial foi incentivar a participação da família no projeto. Para isso, as professoras decidiram produzir a "sacola viajante", uma prática muito comum nas instituições escolares, que consiste numa sacola feita de TNT e EVA, na qual 
a criança leva para casa um livro, que deve ser lido para ela por alguém de sua família e, juntamente com o livro, um caderno, onde a família pode relatar como foi a experiência.

Imagem 1: Foto da sacola viajante com os cadernos de relatos utilizados durante o projeto

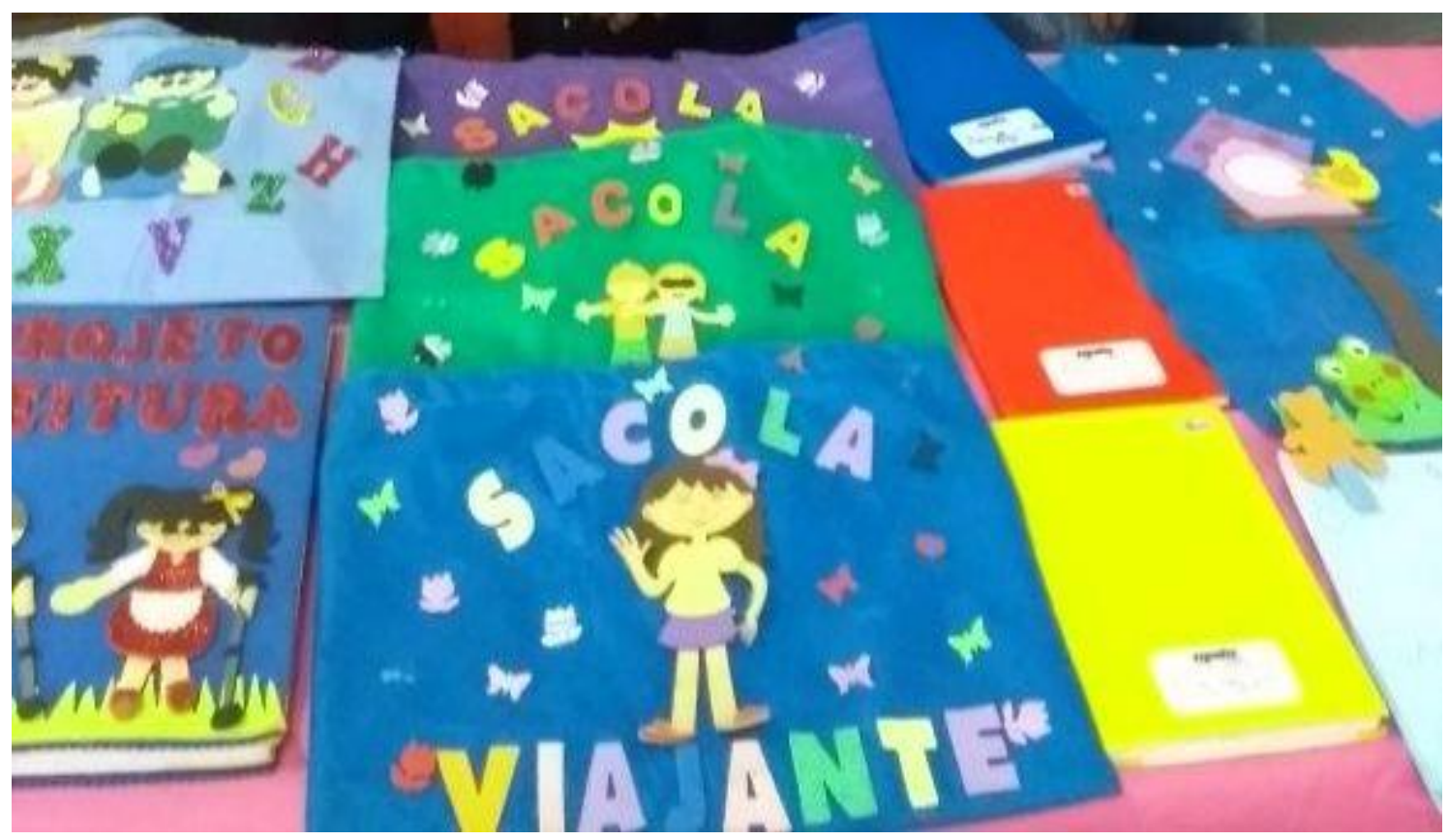

Fonte: acervo da instituição escolar.

As professoras separaram na biblioteca todos os livros que tinham relação com a proposta do projeto. Para essa escolha, contou também com o acervo, apoio e incentivo da professora responsável pela Sala de Recurso Multifuncional (SRM) e Atendimento Educacional Especializado (AEE) da escola.

Foram confeccionadas quatro sacolas de leitura para cada turma e definido que seria feito sorteio para saber quem ia levar a sacola. Os sorteios eram feitos três vezes por semana (segundas, quartas e sextas-feiras). Assim, cada criança ficava dois dias com o livro para que alguém da família lesse para ela, fizesse o relato no caderno e a criança deveria fazer o registro da história por meio de desenho.

O método da sacola de leitura era rotativo, e o procedimento feito por meio de sorteio em sala onde as próprias crianças pegavam o papelzinho com o número sorteado conforme a lista da chamada. Quando a criança retornava com a sacola, a professora lia o relato feito pela família e fazia a exposição do desenho feito pelo aluno para os demais colegas na sala de aula. 
Imagem 2: Fotos dos alunos com a sacola viajante

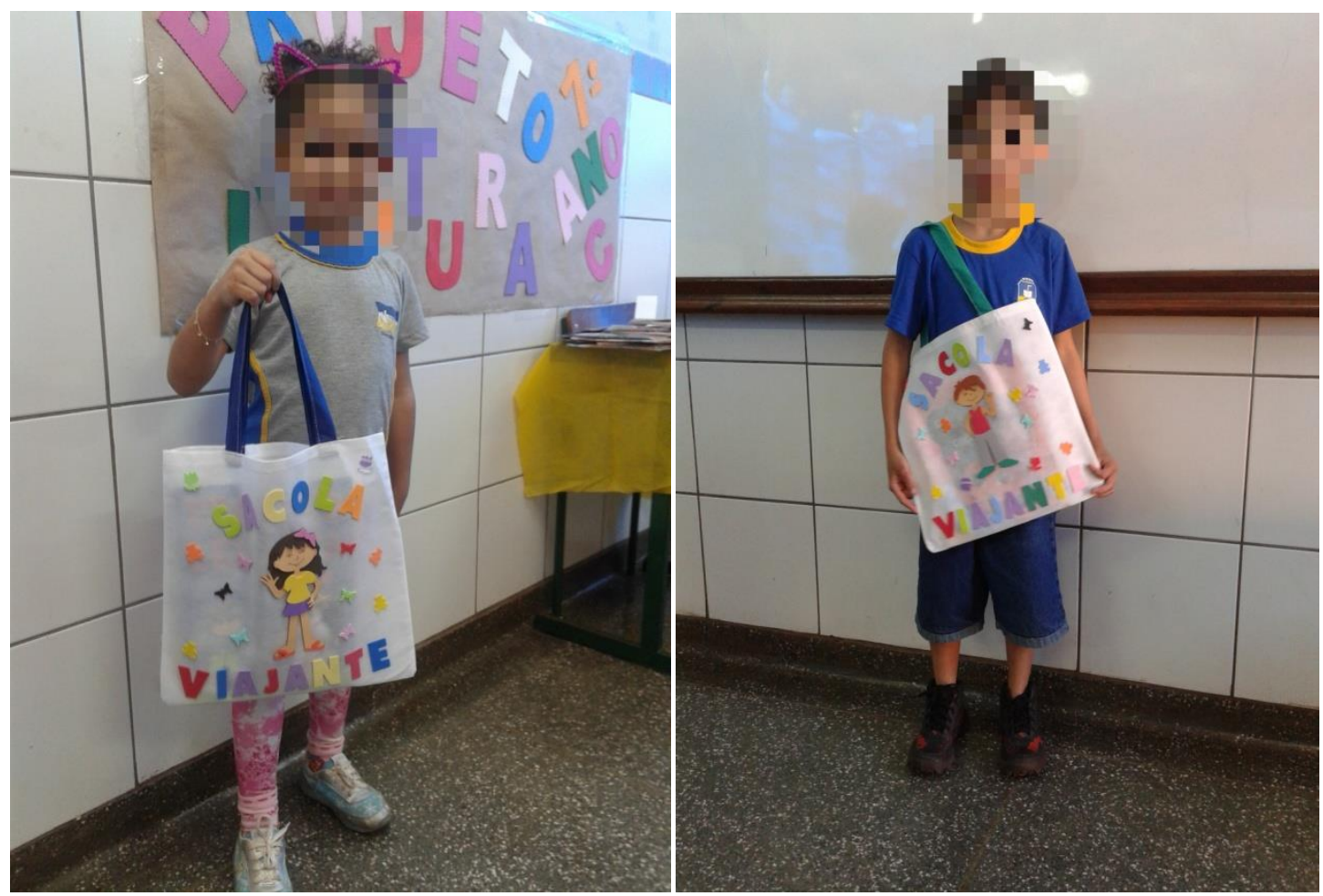

Fonte: acervo da instituição escolar.

É sabido que a participação da família é extremamente importante no processo de ensino e aprendizagem da criança. $\mathrm{O}$ momento de leitura no ambiente familiar reforça o conceito de que a escola é uma continuação da educação familiar, e esse vínculo entre a escola e família devem ser indissociável no processo de aprendizagem do aluno.

Além da sacola de leitura, a visita à biblioteca da escola era constante. Dentro das ações do projeto, a ida à biblioteca estava no planejamento uma vez por semana, momento em que os alunos escolhiam livremente os livros na biblioteca para fazerem a leitura. $\mathrm{Na}$ biblioteca, os alunos podiam escolher os livros, diferente da sacola viajante, onde os livros enviados para leitura familiar eram específicos sobre o tema inclusão escolar e foram previamente escolhidos pela professora responsável pela Sala de Recurso Multifuncional (SRM) especialista em Atendimento Educacional Especializado (AEE) da escola. 
Imagem 3- Fotos dos alunos na biblioteca da escola

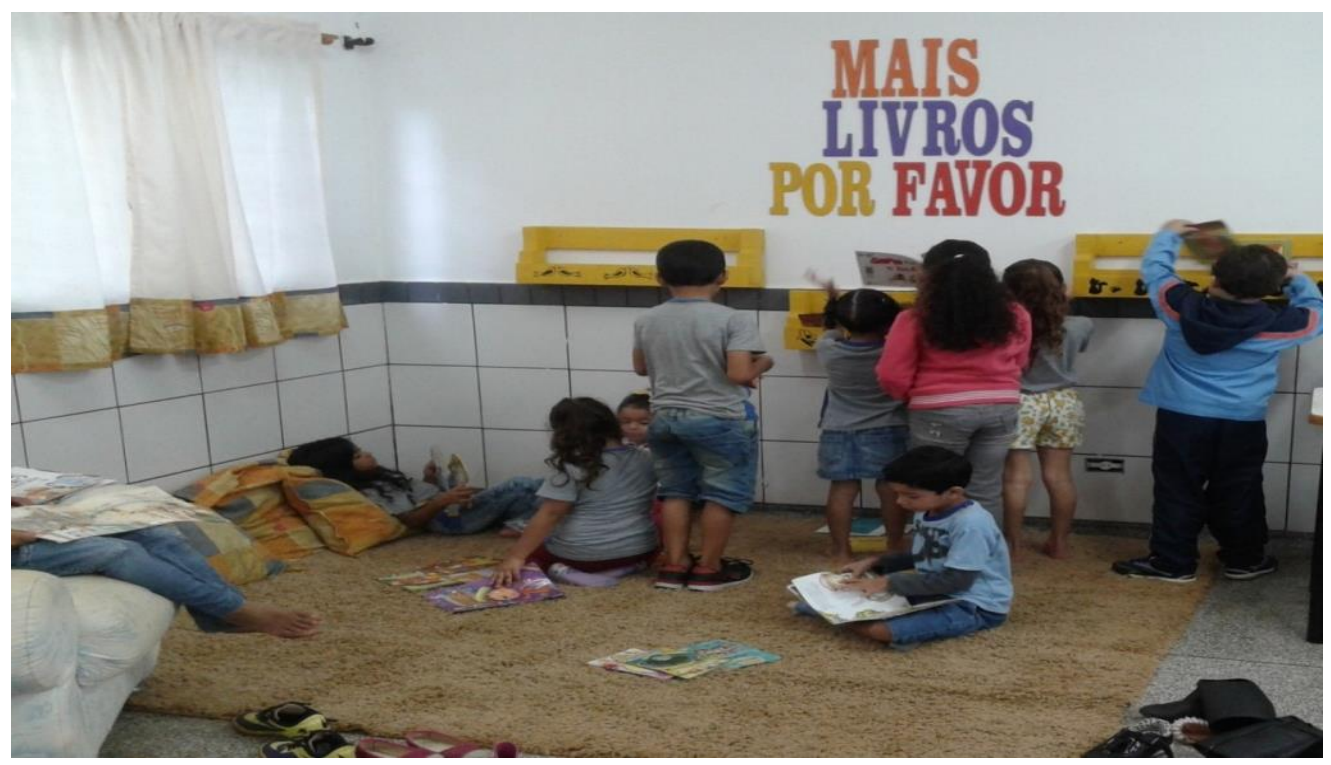

Fonte: acervo da instituição escolar.

O espaço da biblioteca é um espaço amplo e aconchegante, onde as crianças ficavam livres para sentar no tapete ou deitar e assim folhear os livros conforme o interesse da cada um. Momento significativo de aprendizagem, autonomia de desenvolvimento do senso crítico.

No retorno para a sala de aula, sempre as professoras contavam uma história sobre a temática do projeto e desenvolvia o registro das atividades propostas tendo como foco a diferenças dentro do ambiente escolar e valores como: o respeito às diferenças, empatia, afetividade, companheirismo etc.

\section{Imagem 4- Foto de uma das professoras contando história}

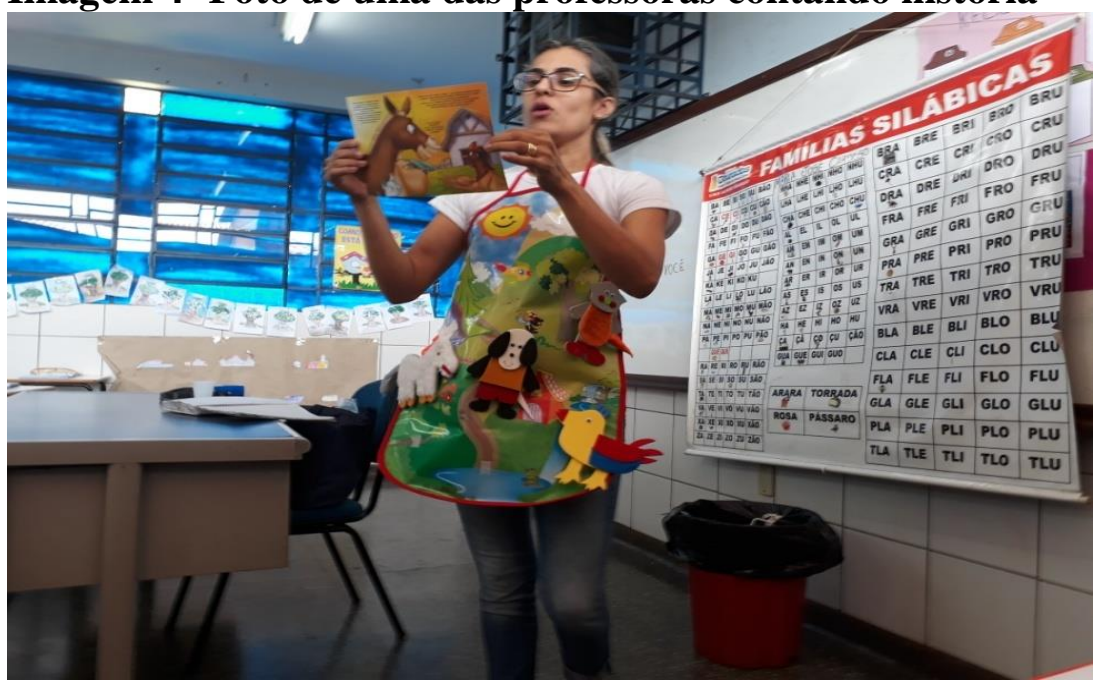

Fonte: acervo da instituição escolar. 
Todas as atividades realizadas durante o desenvolvimento do projeto foram expostas na Feira Cultural Interna da escola, que ocorre todos os anos no final do $4 .^{\circ}$ bimestre, com o objetivo de apresentar para a comunidade interna e externa os trabalhos dos alunos e professores durante o ano letivo.

$\mathrm{Na}$ feira cultural, foram expostas fotos dos alunos durante as atividades escolares do projeto, as sacolas viajantes com os cadernos de relatos e os trabalhos realizados pelas professoras e alunos envolvidos no projeto.

\section{Imagem 5- Foto da exposição dos trabalhos}

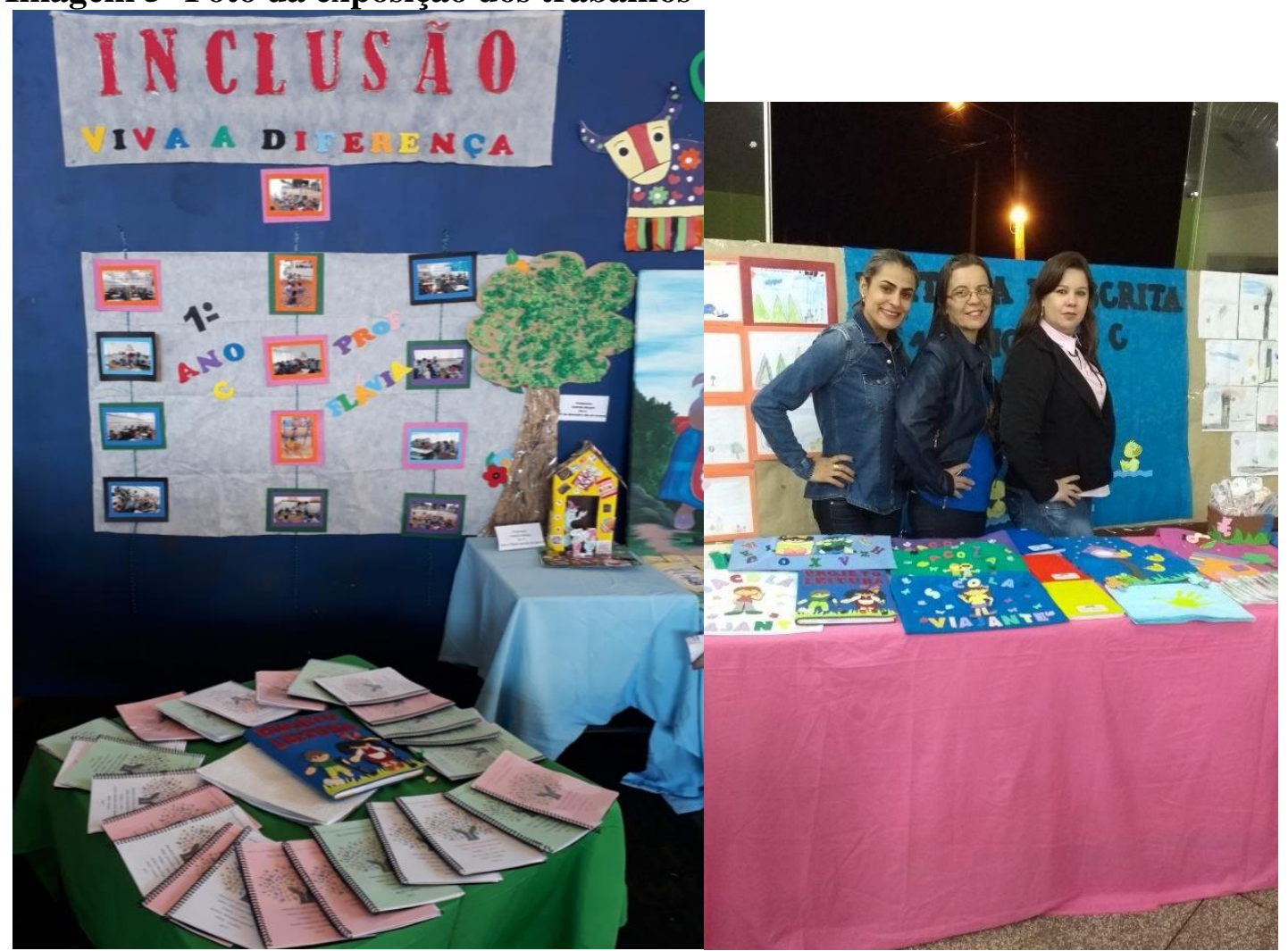

Fonte: acervo da instituição escolar.

E, para finalizar o projeto Leitura e escrita com o tema "Inclusão escolar", as professoras, juntamente com os alunos, realizaram a apresentação de uma dança, momento em que foi apresentada a coreografia da música "Ninguém é igual a ninguém". corroborando as leituras, ações e atividades desenvolvidas ao longo do projeto. 
Imagem 6- Foto da apresentação cultural

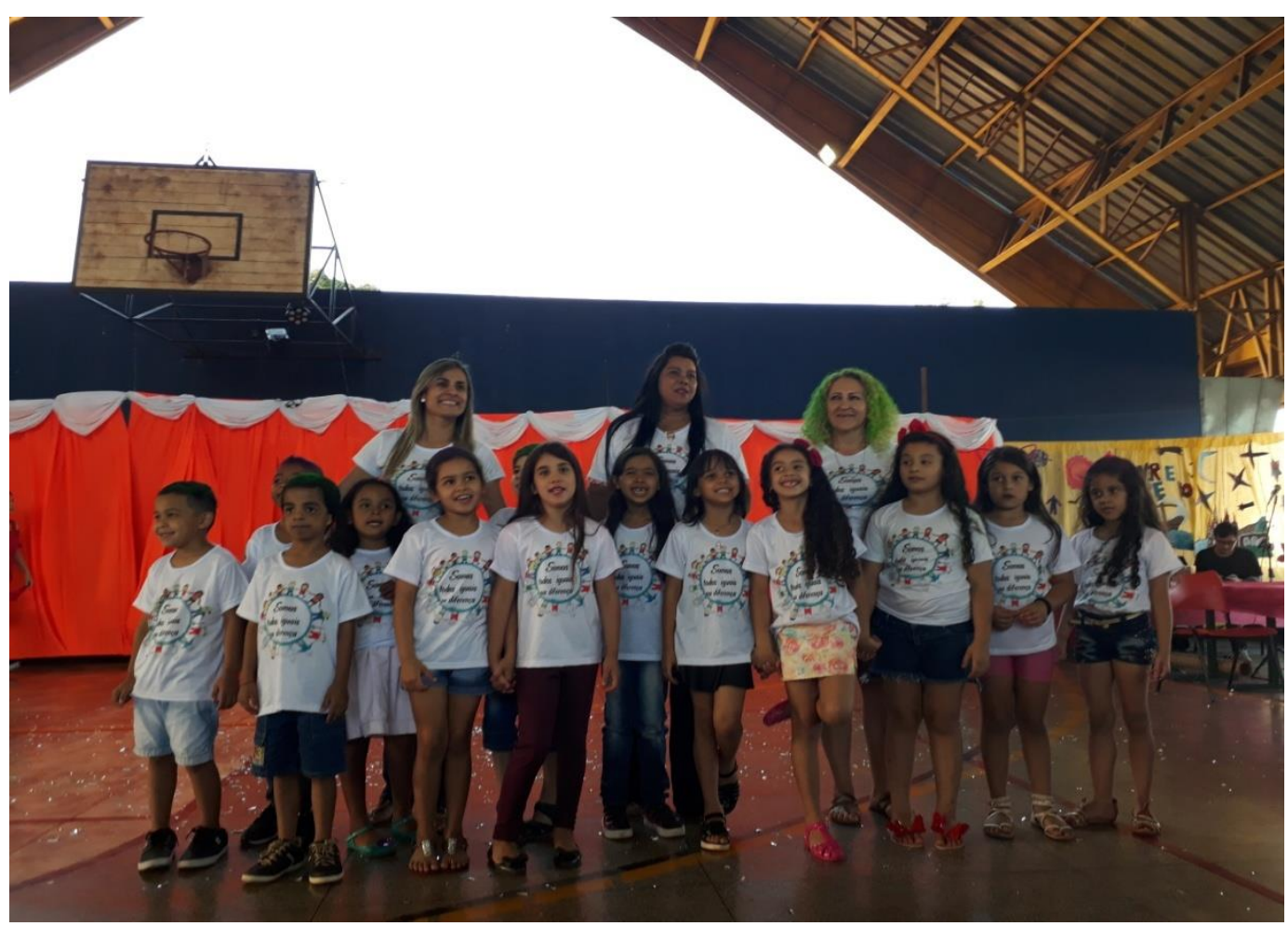

Fonte: acervo da instituição escolar.

\section{RESULTADOS}

O desenvolvimento do projeto leitura e escrita realizado na Escola Municipal Prefeito Alvaro Brandão está inserido num projeto maior, que é um projeto de formação humana, de superação das desigualdades sociais, sejam elas étnica, racial, cultural, religiosa, de gênero etc.

$\mathrm{O}$ acesso à educação, conforme bem evidenciado na Constituição Federal, é direito de todos, e a escola desempenha um papel fundamental na garantia ao acesso e permanência do aluno na instituição.

Com esse entendimento de "direito de todos" conforme rege nossa constituição cidadã, é possível afirmar que, quando toda a escola se empenha na busca da garantia da permanência do aluno com deficiência na instituição escolar, os mesmos, se sentem seguros e aceitos, fomentando possibilidades de um espaço de inclusão e, ao mesmo tempo, fazer com que o estudante se sinta acolhido dentro deste espaço que, enquanto acolhe, inclui. 
E, para que haja a inclusão, é necessário abrir diálogo sobre as diferenças na escola Alvaro Brandão, assim como em toda a rede de ensino de Dourados, seja municipal, estadual ou privada. Os alunos com diferentes deficiências e limitações estão inseridos dentro das escolas. Mas será que estão incluídos?

O projeto "Inclusão escolar" desenvolvido na escola Álvaro Brandão foi significativo no sentido que dialogou com os alunos sobre as deficiências dos colegas que estavam dentro da sala de aula, suas limitações e como encontrar estratégias para superálas. Talvez, pela faixa etária, por se tratar de crianças do primeiro ano do ensino fundamental, houve uma aceitação espontânea abarcando além das habilidades do processo ensino aprendizagem estendendo para uma educação social.

Os resultados observados durante o processo de desenvolvimento do projeto foram: a socialização entre as crianças no momento da escolha dos livros e realização das atividades; a participação mais ativa da família nas atividades de leitura e relato; o protagonismo da criança ao ser feita a leitura do relato em sala de aula e a apresentação do desenho; a autonomia e responsabilidade com a sacola viajante e o livro levados para casa.

E, por fim, pode-se destacar o aprendizado e conhecimento proporcionado na vida das professoras, alunos e familiares. Considera-se que o enfoque "Inclusão Escolar" foi contemplado durante o período de desenvolvimento do projeto, almeja-se que as ações vivenciadas não seja um evento isolado, mas, um acontecimento contínuo que comtemple uma sociedade de fato inclusiva.

\section{REFERÊNCIAS}

BRASIL. Constituição Federal de 1988. República Federativa do Brasil.

DOURADOS. Jornal O Progresso. Dourados, Mato Grosso do Sul. 2015. Disponível em: https://www.progresso.com.br/noticias/prefeito-alvaro-brandao-fez-o-campo-deaviacao-municipal/172108/. Acesso em: 20 jun 2019

DOURADOS. Prefeitura Municipal de Dourados (Site oficial). Dourados, Mato Grosso do Sul. Disponível em: http://www.dourados.ms.gov.br/.Acesso em 14 jun.2019.

DOURADOS. Projeto Político Pedagógico. Escola Municipal Prefeito Alvaro Brandão.2016. 
GARCEZ, L.; CONCEIÇÃO, L. H. de P. Pessoas com deficiências. SDH/PR e Fracso Brasil: Brasília, 2015.

GODOY, Arlinda Schimidt. Introdução à pesquisa qualitativa e suas possibilidades. RAE - Revista de Administração de Empresas, São Paulo, v. 35, n. 2, p. 57-63, 1995. Disponível em: <http://www.scielo.br/scielo.php?script=sci_arttext\&pid=S0034$75901995000200008>$. Acesso em: 19 ago. 2017.

MARQUES, Mario Osório. A aprendizagem na mediação social do aprendido e da docência. 1. ed. Ijuí: Unujuí, 2006.

OLIVEIRA, Ivanilde Apoluceno de; LIMA, Kátia do Socorro Carvalho. Práticas Pedagógicas Inclusivas em sala de aula comum em diálogo com as salas de recursos multifuncionais: atendimento educacional e aprendizagem com sucesso. Educação\&Fronteiras. Vol.5, n.14, Maio/Ago.2015, p.261-288,Dourados,MS: UFGD, 2015

SILVA, Lázara Cristina da. O atendimento educacional especializado na Região CentroOeste do Brasil: indicadores, avanços e limites. In: KASSAR, Monica de Carvalho Magalhães; SILVA, Fabiany de Cássia Tavares (Orgs.). Educação e Pesquisa no Centro-Oeste: processos de escolarização e práticas educativas. Campo Grande, MS: Ed.UFMS, 2012.

SHIROMA, Eneida Oto; CAMPOS, Roselane Fátima; GARCIA, Rosalba Maria Cardoso. Decifrar textos para compreender a política: subsídios teórico-metodológicos para análise de documentos. Revista Perspectiva, Florianópolis, v. 23, n. 02, p. 427-446, jul./dez. 2005. 